\title{
Long-Term Aging Effect on the Crack Growth in the of Main Circulating Pump Casing Material
}

\author{
F. Xue, ${ }^{a}$ W. Yu, ${ }^{\text {b,1 }}$ M. Yu, ${ }^{\text {b W. Liu, }},{ }^{a}$ and G. Shu ${ }^{c}$ \\ a Department of Materials Science and Engineering, Tsinghua University, Beijing, China \\ ${ }^{\mathrm{b}}$ Suzhou Nuclear Power Research Institute, Suzhou, China \\ ${ }^{c}$ China Nuclear Power Engineering Co, Ltd, Shenzhen, China \\ ${ }^{1}$ yuweiwei@cgnpc.com.cn
}

Fatigue crack growth (FCG) tests on the main circulating pump casing material were conducted at room temperature to investigate the effect of long-term aging at $400^{\circ} \mathrm{C}$. It was found that the $F C G$ rate increased with aging time. However, there were similar $\Delta K_{\text {th }}$ values for both the virgin material and aged material at the same stress ratios $R$. At room temperature, $\Delta K_{\text {th }}$ was observed to decrease with an increase in $R$. An equation incorporating the $K_{\max }$ and $\Delta K$ effects was proposed to describe FCG rates over the linear portion of the curve (Paris equation) for all stress ratios. Additionally, fatigue fracture patterns near crack initiation sites reveals quasi-cleavage fracture in thermally aged specimens.

Keywords: crack growth, thermal aging, main pump casing, AP1000 reactor.

Introduction. A hermetically sealed, wet winding motor type circulating pump has been specially designed for an AP1000 reactor. For each of the two steam generators, two pump casings are welded to the channel head by the suction nozzle. Since the pump casing is insulated to reduce heat losses, while the system temperature can reach up to $280^{\circ} \mathrm{C}$ with a pressure of $15.5 \mathrm{MPa}$ during the operation, the long-term aging mechanism should be considered in the performance of the casing material.

Cast stainless steels (CASS) are the preferred choice for pump casing due to their adequate strength and corrosion resistance. Although CASS consist of $\alpha$-ferrite and $\gamma$-austentie phases, a spinodal decomposition may occur in the $\alpha$-phase, which decomposes into a Fe-rich $\alpha$-phase and a Cr-rich $\alpha^{\prime}$-phase, thus reducing the mechanical properties [1, 2]. Kang et al. [3] studied a type of CASS with the base composition of $25.5 \mathrm{Cr}-6 \mathrm{Ni}-3.5 \mathrm{Mo}$ aged at $900^{\circ} \mathrm{C}$ for $30 \mathrm{~min}$ after homogenization and showed that the apparent FCG resistance was significantly improvede, which could be attributed to the roughness-induced crack closure due to the existence of brittle secondary phases precipitated during the aging. Kwon et al. [4] reported that FCG rate of the CF8M degradation at $700^{\circ} \mathrm{C}$ is larger than that of the thermally degraded one at $430^{\circ} \mathrm{C}$. Balbi et al. [5] found that the crack nucleation mechanism in SAF 2205 CASS material may change due to the long-term aging. In the virgin material, cracks mainly nucleated at grain and phase boundaries or second-phase particles, while in the aged condition, slip marks first appeared in the ferritic phase and became the preferred site for the microcrack nucleation. However, limited studies are conducted to test the effect of aging on the FCG behavior of cast main circulating pump casing material, especially for the material used in AP1000 nuclear power stations (NPP).

Therefore, the object of the present study is the long-term aging effect on fatigue crack growth rate of the cast CF8A material. The main input data for fatigue life prediction of the main circulating pump casing are also obtained within framework of this study.

1. Experimental Procedures. The material under study is CF8A cast stainless steel, which is a domestic production for AP1000 main circulating pump casings supplied by CFHI. Table 1 shows the chemical composition of the material. The microstructure of the 
Long-Term Aging Effect on the Crack Growth ...

$\mathrm{T}$ a $\mathrm{b} 1 \mathrm{e} 1$

Chemical Composition of CF8A (wt.\%)

\begin{tabular}{|c|c|c|c|c|c|c|c|c|c||}
\hline $\mathrm{C}$ & $\mathrm{Si}$ & $\mathrm{Mn}$ & $\mathrm{P}$ & $\mathrm{S}$ & $\mathrm{Cr}$ & $\mathrm{Mo}$ & $\mathrm{Ni}$ & $\mathrm{Co}$ & $\mathrm{N}$ \\
\hline$\leq 0.080$ & $\leq 2.0$ & $\leq 1.50$ & $\leq 0.040$ & $\leq 0.0400$ & $18-21$ & $\leq 0.50$ & $8-11$ & - & - \\
0.019 & 0.8 & 0.88 & 0.011 & 0.0044 & 20.18 & 0.19 & 8.2 & 0.05 & $339 \mathrm{ppm}$ \\
\hline
\end{tabular}

virgin material is composed of islands of ferrite embedded into austenite matrix, while ferrite content of the virgin material is about $10.5 \%$.

The local enrichment of $\mathrm{Cr}$ caused by the spinodal decomposition or $\alpha^{\prime}$-phase precipitation in the ferrite phase is responsible for the embrittlment of the thermally aged materials. The material was heat-treated for 500, 1000, 3000, and $6000 \mathrm{~h}$, respectively, at $400^{\circ} \mathrm{C}$, which is the maximal value in the temperature range of the spinodal decomposition, above which other degradation mechanisms can be exhibited by this material [6-8].

The dimensions of the test specimens, which comply with the ASTM E647-2012 stadard, are shown in Fig. 1. FCG tests were carried out in ambient air using an MTS 810 servo-controlled electrohydraulic testing machine. A fatigue pre-crack was introduced by the $K$-decreasing technique. During the test, the crack length was monitored using the compliance method. All specimens were pre-cracked to a depth of at least $2 \mathrm{~mm}$ from the crack tip and were subsequently tested at the constant load amplitude with a sinusoidal waveform. The FCG test frequency was kept at $12 \mathrm{~Hz}$. To study the effect of stress ratio $R=K_{\min } / K_{\max }$ on crack growth rate, tests were conducted with stress ratios $R$ equal to $0.1,0.3$, and 0.5 .
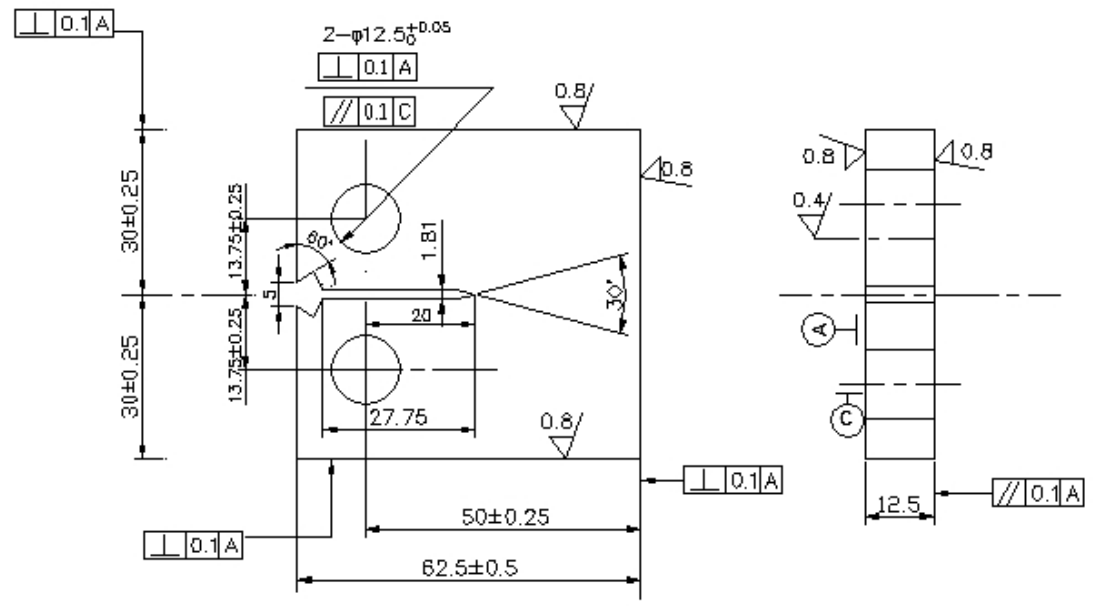

Fig. 1. Schematic diagrams showing the configuration of the compact-tension (CT) specimens.

An Tescan VEGA TS 5136XM scanning microscope was used to examine the microstructure of the specimens under different aging conditions and the fatigue crack propagation paths.

\section{Results and Discussion.}

2.1. Stress Ratio Effect. The relationships between the FCG rate and stress intensity factor (SIF) range at room temperature for both virgin and aged material with different loading ratios are shown in Fig. 2. The material displays a significant effect of the stress ratio on the crack growth rate: within an identical SIF range, a higher stress ratio results in a higher crack growth rate, while the threshold tendency indicates that the SIF threshold value decreases with stress ratio. 


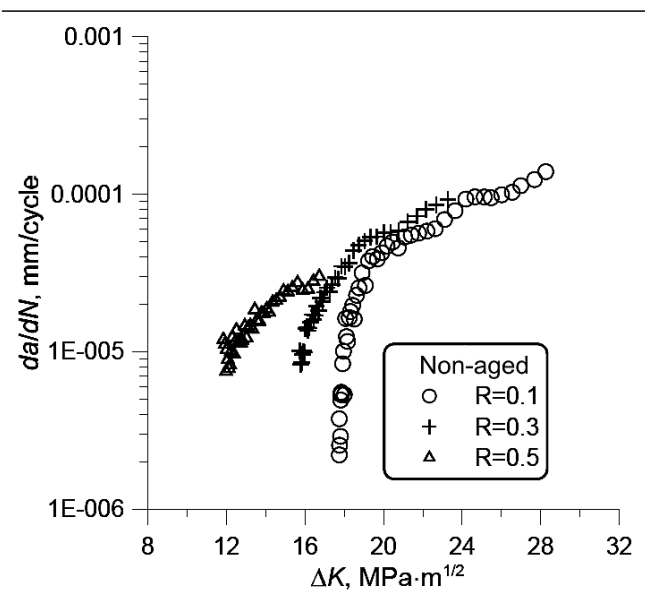

$\mathrm{a}$

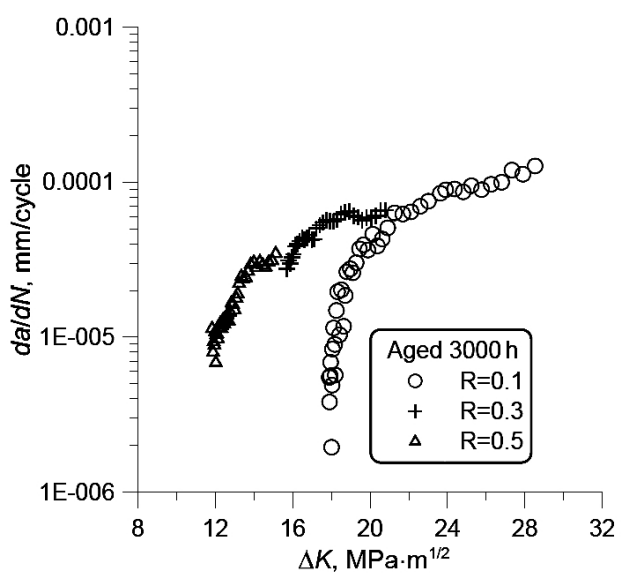

C

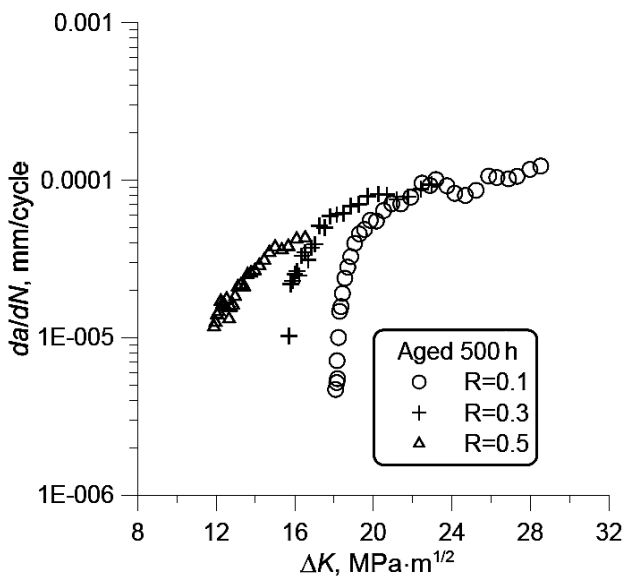

$\mathrm{b}$

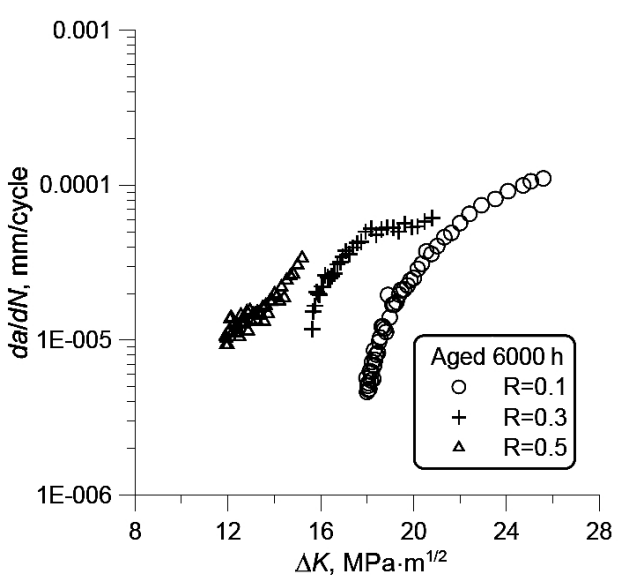

d

Fig. 2. Fatigue crack growth rates as a function of stress intensity range at room temperature with aging conditions: (a) non-aged; (b) $500 \mathrm{~h}$; (c) $3000 \mathrm{~h}$; (d) $6000 \mathrm{~h}$ at $400^{\circ} \mathrm{C}$.

Above the low crack growth rate region $\left(d a / d N>10^{5} \mathrm{~mm} /\right.$ cycle $)$ or within the so-called Paris regime, the FCG curves exhibit linear relationships between logarithmic values of FCG rate $d a / d N$ and SIF range $\Delta K$, which can be expressed as

$$
d a / d N=C(\Delta K)^{m},
$$

where $C$ is a constant and $m$ is the curve slope in the $\log -\log$ plot. It is reported that $C$ is a function of the stress ratio, but $m$ is nearly independent of $R$ [9]. It is also known that when crack growth behavior depends on both $\Delta K$ and $K_{\text {max }}$, the crack growth curve can be described by the following equation $[10,11]$ :

$$
d a / d N=C^{\prime}(\Delta K)^{\alpha}\left(K_{\max }\right)^{\beta} .
$$

Equation (2) can be correlated with Eq. (1) by introducing $\Delta K(1-R)$, such that $m=\alpha+\beta$ and $C=C^{\prime}(1-R)^{\beta}$. Figures $3 \mathrm{a}$ and $3 \mathrm{~b}$ depict the correlated data using Eq. (2) along with the corresponding best-fit line, while the parameters for Eqs. (1) and (2) are 
listed in Table 2. For the tested metals, it can be found that $\alpha>\beta$, indicating that fatigue crack growth rate is controlled by $\Delta K$, while the crack advance occurs via an intrinsic mechanism, such as the alternating crack tip blunting and re-sharpening. Moreover, a high value of $\alpha$, as compared to $\beta$, indicates that the crack growth behavior is predominantly cycle-dependent under the test conditions.

T a b 1 e 2

Parameters for FCG Models in the Paris Regime

\begin{tabular}{|c|c|c|c|c|c|c|c|c|}
\hline Spec. & $R$ & $\begin{array}{c}\text { Aged } \\
\text { time, } \mathrm{h}\end{array}$ & $C$ & $m$ & $C^{\prime}$ & $\alpha$ & $\beta$ & $R^{2}$ \\
\hline AG1 & 0.1 & 0 & $1.546 \mathrm{E}-09$ & 3.414 & $1.408 \mathrm{E}-09$ & 2.733 & 0.691 & 0.986 \\
\hline AG2 & 0.3 & & $1.402 \mathrm{E}-09$ & 3.531 & & & & \\
\hline AG3 & 0.5 & & $1.784 \mathrm{E}-09$ & 3.491 & & & & \\
\hline BG1 & 0.1 & 500 & 6.839E-08 & 2.248 & $1.002 \mathrm{E}-07$ & 1.920 & 0.210 & 0.931 \\
\hline BG2 & 0.3 & & $1.956 \mathrm{E}-07$ & 1.974 & & & & \\
\hline BG3 & 0.5 & & 2.918E-09 & 3.456 & & & & \\
\hline CG1 & 0.1 & 1000 & 8.589E-09 & 2.941 & 8.496E-09 & 2.164 & 0.749 & 0.920 \\
\hline CG2 & 0.3 & & 2.592E-09 & 3.461 & & & & \\
\hline CG3 & 0.5 & & $1.606 \mathrm{E}-10$ & 4.559 & & & & \\
\hline DG1 & 0.1 & 3000 & $3.505 \mathrm{E}-09$ & 3.149 & $1.229 \mathrm{E}-08$ & 2.121 & 0.622 & 0.944 \\
\hline DG2 & 0.3 & & $3.380 \mathrm{E}-07$ & 1.748 & & & & \\
\hline DG3 & 0.5 & & $4.713 \mathrm{E}-12$ & 5.874 & & & & \\
\hline FG1 & 0.1 & 6000 & $1.265 \mathrm{E}-11$ & 4.951 & $2.115 \mathrm{E}-10$ & 2.760 & 1.267 & 0.973 \\
\hline FG2 & 0.3 & & $6.008 \mathrm{E}-10$ & 3.848 & & & & \\
\hline FG3 & 0.5 & & $3.370 \mathrm{E}-10$ & 4.157 & & & & \\
\hline
\end{tabular}

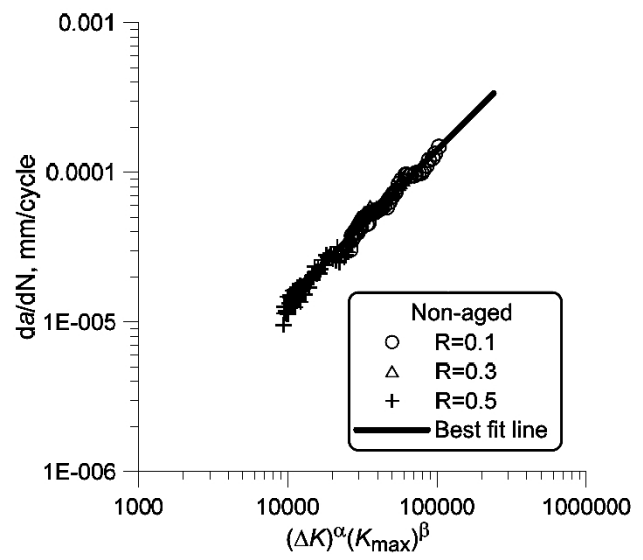

a

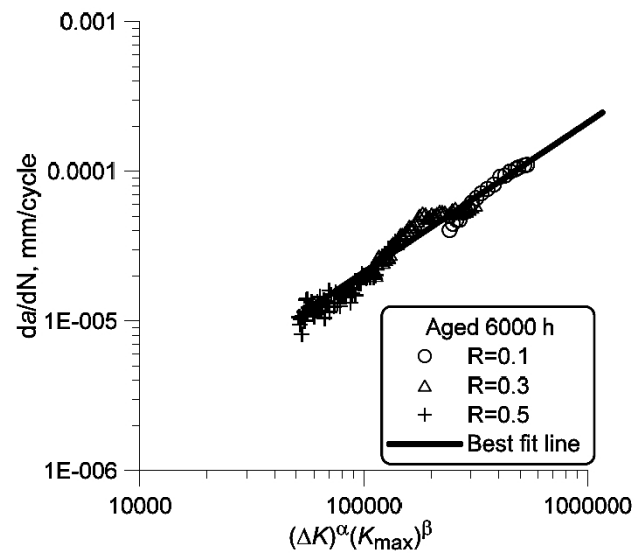

b

Fig. 3. Data fit via Eq. (2) for non-aged (a) and aged for $6000 \mathrm{~h} \mathrm{(b)} \mathrm{materials.}$

2.2. Aging Effects. The $d a / d N-\Delta K$ curves for the virgin material and four classes of specimens degraded at $400^{\circ} \mathrm{C}$ are depicted in Fig. $4 \mathrm{a}-\mathrm{c}$ for different stress ratios. The crack growth rates of the aged material are higher than those of the virgin material, while 


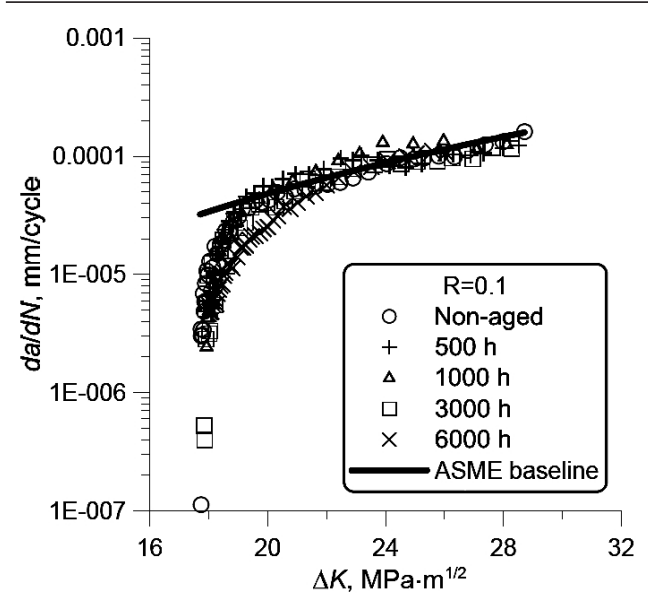

a

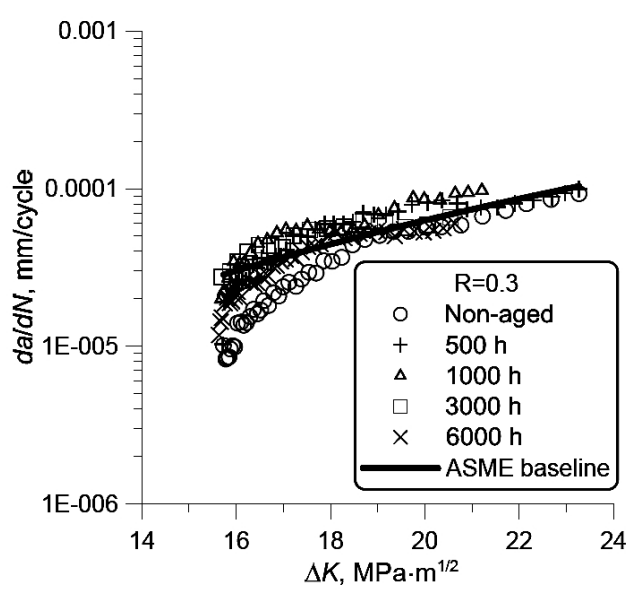

b

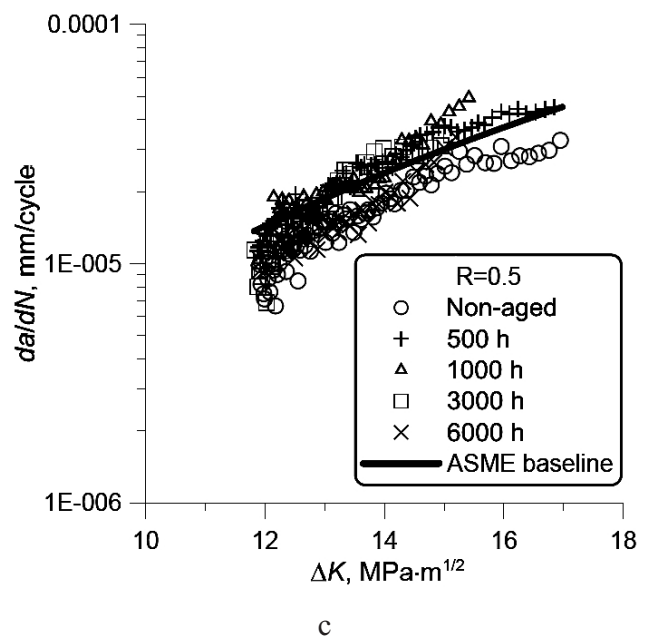

Fig. 4. Relationship between $d a / d N$ and $\Delta K$ for different aging periods at $R=0.1$ (a), $R=0.3$ (b), and $R=0.5$ (c).

the stress ratio $R$ strongly affects the FCG parameters. The results also indicate that the material of the main circulating pump casing shows a susceptibility to thermal embrittlement.

In ASME SEC XI D1 NMA APP C8410, the reference fatigue crack growth model of cast and wrought/forge austenitic stainless steels and their welds exposed to air environment is described by Eq. (1) with $m=3.3$,

$$
\left\{\begin{array}{l}
d a / d N=C_{0}(\Delta K)^{3.3}, \\
C_{0}=C S,
\end{array}\right.
$$

where $C$ is a scaling parameter, which accounts for the temperature and is determined as follows:

$$
C=10^{\left(-8.714+1.34 \cdot 10^{-3} T-3.34 \cdot 10^{-6} T^{2}+5.95 \cdot 10^{-9} T^{3}\right)},
$$

where $T$ is the metal temperature in ${ }^{\circ} \mathrm{C}$ [for $T \leq 430^{\circ} \mathrm{C}$ ], and $S$ is a scaling parameter to account for the stress ratio $R$, which is calculated as follows: 


$$
S= \begin{cases}1.0+1.8 R, & 0<R \leq 0.79, \\ -43.35+57.97 R, & 0.79<R<1.0 .\end{cases}
$$

The FCG curves for the virgin material obtained is this study are mainly located below the ASME-model curve constructed via Eqs. (3)-(5). Since the thermal aging process accelerates the FCG rate, the majority of test results on the aged material are above this baseline, which means that the aged material does not satisfy the ASME design rule. The dependency of FCG rate on the stress ratio, when $\Delta K$ is used as the correlating parameter, is mainly attributed to the crack closure [12].

The threshold level $\left(\Delta K_{t h}\right)$, as the SIF level, below which the FCG rate $d a / d N$ becomes very low, is very critical in assessing the resistance of material to FCG. Although only few threshold values were measured at very low crack growth rate levels, it is clear from the near-threshold data that the $\Delta K_{\text {th }}$ at $R=0.1$ was higher than those at higher stress ratios. As can be seen from Fig. 4, that there is almost no difference in the FCG resistance characteristcs of the material under different aging conditions, especially at the early FCG stages, which fact is also confirmed by Fig. 5.

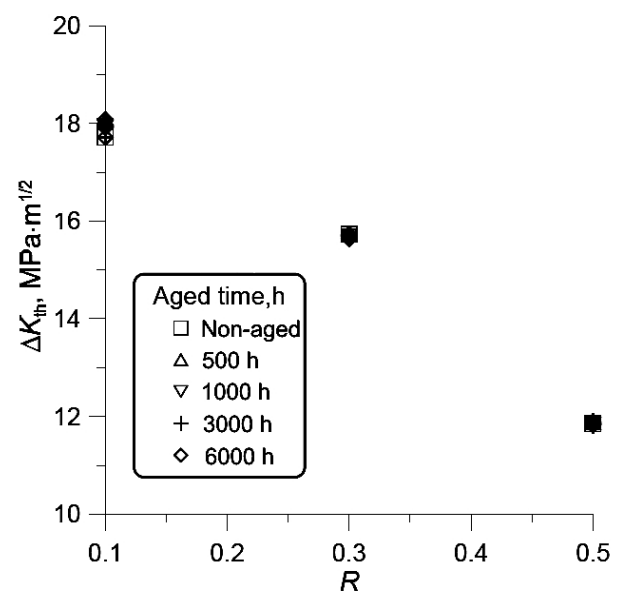

Fig. 5. Experimental determined threshold $\Delta K_{\text {th }}$ as a function of stress ratio $R$.

2.3. Fractographic Studies. SEM fractographs of FCG specimens tested at different stress ratios and aging conditions are shown in Fig. 6. Fracture patterns corresponding to the low and intermediate $\Delta K$ regimes of the cast main circulating pump casing material are mainly related to transgranular fatigue fracture and faceted crystallographic failure. A more pronounced change of the fracture pattern is observed in the fractographs of the specimens aged for $3000 \mathrm{~h}$, which reveal a quasi-cleavage fracture of the aged specimens (Fig. $6 \mathrm{~g}$ and $6 \mathrm{~h}$ ). The accelerated crack growth in the aged specimens can be attrributed to the brittle fracture induced by thermal aging. Meanwhile, the share of faceted failure cases decreases and eventually disappears in the high $\Delta K$ regime, where fatigue striations at the fatigue-fractured surface are evident in the specimens with $R=0.1$ (Fig. 6c and 6i). However, fatigue striations disappear at high stress ratio $R=0.5$ (Fig. 6f). In the virgin material, there are relatively smooth areas, which are indicative of predominantly transgranular fatigue propagation and contain fairly well-developed striations. The latter exhibit a widely dispersed microvoid formation around second-phase particles, which are marked in Fig. 6c. Figure 6i illustrates a less pronounced occurrence of microvoids (as compared with Fig. 6c), which also indicates the influence of thermal aging on the cracking behavior of material. 


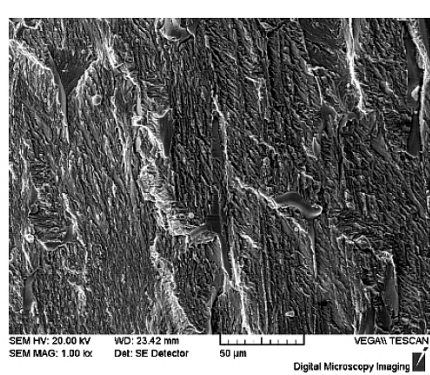

a

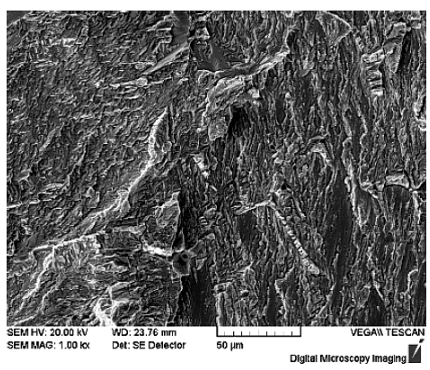

d

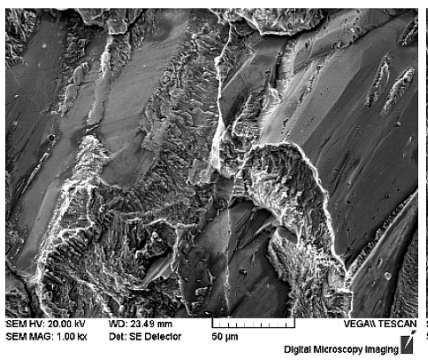

g

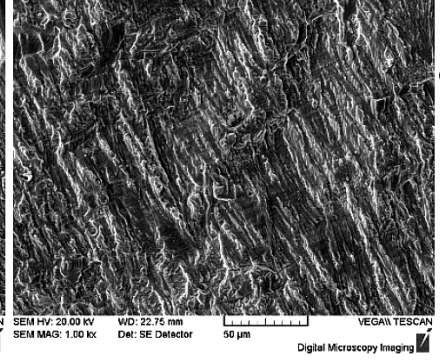

$\mathrm{b}$

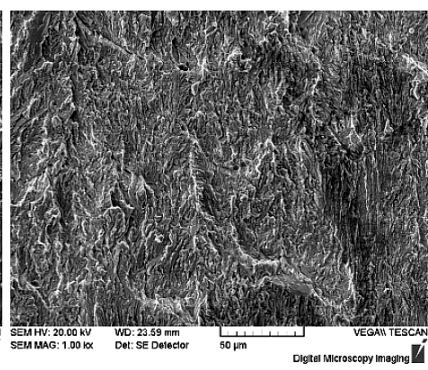

$\mathrm{e}$

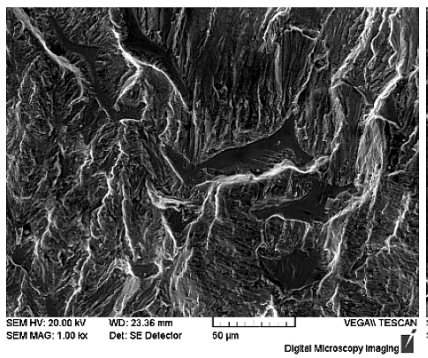

$\mathrm{h}$

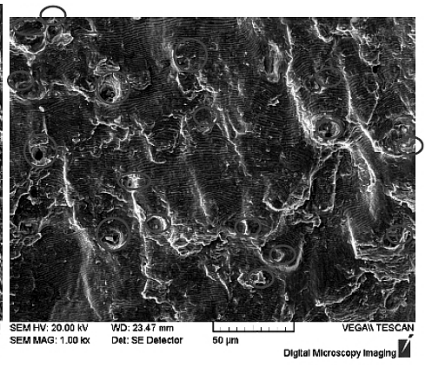

C

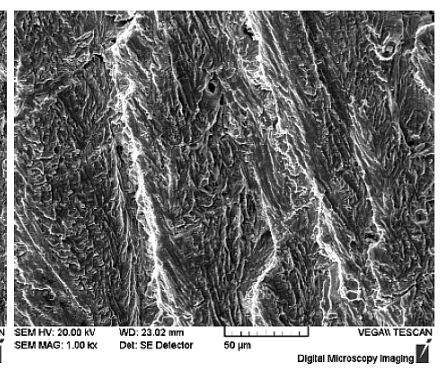

$\mathrm{f}$

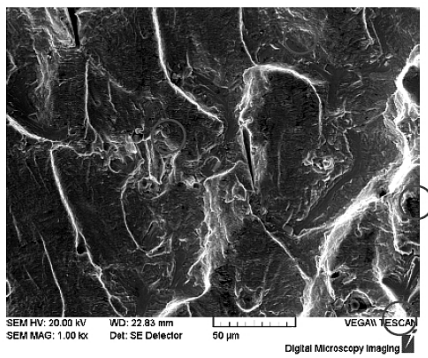

$\mathrm{i}$

Fig. 6. Fractographs of FCG regions in the specimen tested at different stress ratios and aging conditions: (a) $R=0.1$, non-aged, and low $\Delta K$; (b) $R=0.1$, non-aged, and intermediate $\Delta K$; (c) $R=0.1$, non-aged, and high $\Delta K$; (d) $R=0.5$, non-aged, and low $\Delta K$; (e) $R=0.5$, non-aged, and intermediate $\Delta K$; (f) $R=0.5$, non-aged, and high $\Delta K$; (g) $R=0.1$, aged $3000 \mathrm{~h}$, and low $\Delta K$; (h) $R=0.1$, aged $3000 \mathrm{~h}$, and intermediate $\Delta K$; (i) $R=0.1$, aged $3000 \mathrm{~h}$, and high $\Delta K$.

Conclusions. This study discusses the FCG behavior of the cast AP1000 main circulating pump casing material under different aging conditions. Based on the FCG test results and their analysis, the following conclusions can be drawn.

1. The tested material FCG rate at the stress ratios $R=0.1,0.3$, and 0.5 increases with the aging time.

2. As compared with the virgin material, the above-mentioned FCG increase may exceed the ASME design baseline for stainless steels.

3. The long-term aging at $400^{\circ} \mathrm{C}$ generally has no effect on the FCG threshold $\Delta K_{\text {th }}$ values.

4. FCG rates in the Paris regime for all studied stress ratios are adequately controlled by equation (2), which incorporates the effects of SIFs: $K_{\max }$ and $\Delta K$.

5. The crack initiation sites of FCG test specimens with different aging conditions mainly indicate quasi-cleavage fracture patterns. 
6. In high $\Delta K$ loading regimes, the stress ratio $R$ has a strong effect on formation of fatigue striations.

Acknowledgments. The financial support from National Science and Technology Major Project (2011ZX06004-009) is greatly acknowledged.

1. F. Iacoviello, F. Casari, and S. Gialanella, "Effect of $475^{\circ} \mathrm{C}$ embrittlement on duplex stainless steels localized corrosion resistance," Corros. Sci., 47, 909-922 (2005).

2. Z. X. Wang, F. Xue, J. Jiang, et al., "Experimental evaluation of temper aging embrittlement of cast austenitic stainless steel from PWR," Eng. Fail. Anal., 18, No. 1, 403-410 (2011).

3. T. H. Kang, D. M. Li, Y. D. Lee, and C. S. Lee, "Alloying and aging effects on the fatigue crack growth of duplex stainless steels," Mater. Sci. Eng. A, 251, 192-199 (1998).

4. J. D. Kwon, J. C. Park, Y. S. Lee, et al., "An investigation of the degradation characteristics for casting stainless steel, CF8M, under high temperatures," Nucl. Eng. Des., 198, 227-240 (2000).

5. M. Balbi, M. Avalos, A. El Bartali, and I. Alvarez-Armas, "Microcrack growth and fatigue behavior of a duplex stainless steel," Int. J. Fatigue, 31, 2006-2013 (2009).

6. F. Danoix and P. Auger, "Atom probe studies of the $\mathrm{Fe}-\mathrm{Cr}$ system and stainless steels aged at intermediate temperature: a review," Mater. Charact., 44, 177-201 (2000).

7. V. T. Jelena, B. Sustarsic, and F. Vodopivec, "The effect of ageing temperature and time on the mechanical properties of FeNiCrMo alloys with different contents of ferrite," Nucl. Eng. Des., 238, 1511-1517 (2008).

8. Z. X. Wang, F. Xue, W. H. Guo, et al., "Investigation of thermal aging damage mechanism of the cast duplex stainless steel," Nucl. Eng. Des., 240, 2538-2543 (2010).

9. V. M. J. Sharma, K. Sree Kumar, B. Nageswara Rao, and S. D. Pathak, "Fatigue crack growth of AA2219 under different aging conditions," Mater. Sci. Eng. A, 528, 4040-4049 (2011).

10. J. P. Campbell, K. T. Venkateswara Rao and R. O. Ritchie, "Fatigue-crack growth and fracture behavior in a XD\&trade; $\gamma$-TiAl alloy with a fine lamellar microstructure," in: G. Lüterjing and H. Nowack (Eds.), Fatigue'96 (Proc. of the Sixth Int. Congr. on Fatigue), Vol. III, Pergamon Press, Oxford, UK (1996), pp. 1779-1784.

11. J. Zhao, Y. Miyashita, and Y. Mutoh, "Fatigue crack growth behavior of $95 \mathrm{~Pb}-5 \mathrm{Sn}$ solder under various stress ratios and frequencies," Int. J. Fatigue, 22, 665-673 (2000).

12. N. E. Dowling, Mechanical Behavior of Materials: Engineering Methods for Deformation, Fracture, and Fatigue, Prentice-Hall International, New Jersey (1993). 